\title{
INFLUENCE OF FILM THICKNESS ON THE MICROSTRUCTURE AND MAGNETIC PROPERTIES OF FINEMETIC THIN FILMS
}

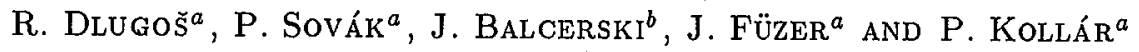 \\ ${ }^{a}$ Faculty of Science, P.J. Safárik University, Park Angelinum 9, 04154 Košice, Slovakia \\ ${ }^{b}$ Department of Solid State Physics, University of Eódź \\ Pomorska 149/153, 90-236 Łódź, Poland
}

\begin{abstract}
The aim of this work was to study the influence of film thickness on the structure and magnetic properties of finemetic thin films after annealing. Thin films with the various thickness (from $20 \mathrm{~nm}$ up to $700 \mathrm{~nm}$ ) were prepared by DC sputtering method. The heat treatments of the films for further structural and magnetic observations were performed at the temperature range $300-500^{\circ} \mathrm{C}$ for $15 \mathrm{~min}$ in vacuum furnace. Structural observations were carried out by transmission electron microscopy. Coercivity was determined from hysteresis loops traced with fluxmeter and Kerr magnetooptical hysteresisgraph. All the experimental results confirm a different magnetic behaviour of the thin films according to their thickness.
\end{abstract}

PACS numbers: $68.55 . \mathrm{Jk}, 73.50 . \mathrm{Jt}, 75.70 . \mathrm{Ak}$

\section{Introduction}

It is generally known that in amorphous and crystalline ferromagnetic thin films like permalloy, coercivity increases with decreasing film thickness. This fact can be attributed to preparation related defects, like surface roughness, the relative contribution of which increases with decreasing thickness [1,2].

In this paper we investigate the influence of film thickness on the structure and magnetic properties of annealed finemet-type thin films.

\section{Experimental methods}

Thin films of composition $\mathrm{Fe}_{73.5} \mathrm{Cu}_{1} \mathrm{Nb}_{3} \mathrm{Si}_{13.5} \mathrm{~B}_{9}$ of $25 \mathrm{~nm}, 100 \mathrm{~nm}, 200 \mathrm{~nm}$, $700 \mathrm{~nm}$ thickness were prepared by ion beam sputtering onto glass and freshly cut rock salt (for magnetic measurements and transmission electron microscopy (TEM) observations, respectively) at room temperature using target which was made of about $30 \mu \mathrm{m}$ thick amorphous ribbons of the same composition. The samples for magnetic measurements were covered by the protective SiO film after film sputtering immediately. In order to change the microstructure the films were 
annealed at temperatures $250^{\circ} \mathrm{C}, 300^{\circ} \mathrm{C}, 350^{\circ} \mathrm{C}, 400^{\circ} \mathrm{C}, 450^{\circ} \mathrm{C}$, and $500^{\circ} \mathrm{C}$ for 15 min in vacuum furnace. Structural observations were carried out by TEM. To compare results obtained by surface layer and bulk measurements of coercivity Kerr magnetooptical hysteresisgraph and fluxmeter were used. Dependence of the Hall coefficient $R_{1}$ on the annealing temperature was obtained from the Hall curves measured by $\mathrm{DC}$ method at room temperature.

\section{Results and discussion}

TEM confirmed amorphicity of all the prepared samples. No significant influence of the film thickness (up to $100 \mathrm{~nm}$ ) on their structure was observed. Amorphicity of thicker samples was confirmed by X-ray diffraction (XRD). Figure 1 shows influence of annealing treatment on the film structure. Heat treatment at $350^{\circ} \mathrm{C}$ (Fig. 1a) starts the partial crystallization of all the samples. It is an initial stage of the crystallization process with low volume fraction of homogeneously dispersed FeSi crystals in amorphous matrix with high nucleation density, similarly as for nanocrystalline finemet-type ribbons. The mean grain size of the crystals is about $10 \mathrm{~nm}$. Figure $1 \mathrm{~b}$ shows nanocrystalline structure of the samples annealed at $400^{\circ} \mathrm{C}$ with the presence of crystals of about $30 \mathrm{~nm}$. Annealing at $450^{\circ} \mathrm{C}$ caused that all the samples were fully crystallized with mean grain size of about $50 \mathrm{~nm}$ (Fig. 1c). Annealing at $500^{\circ} \mathrm{C}$ leads to grain coarsening up to $100 \mathrm{~nm}$ and precipitation of borides (Fig. 1d).

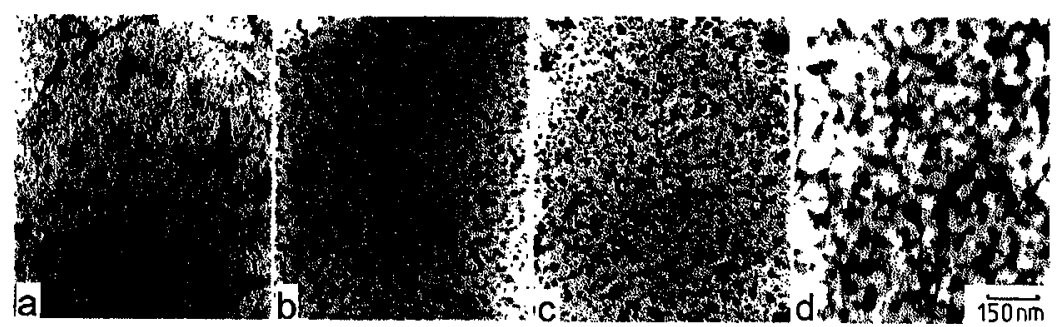

Fig. 1. TEM microphotographs of the samples annealed at (a) $350^{\circ} \mathrm{C}$, (b) $400^{\circ} \mathrm{C}$, (c) $450^{\circ} \mathrm{C}$, and (d) $500^{\circ} \mathrm{C}$.

Figure 2a shows the temperature dependence of surface layer coercivity on film thickness. The decrease in coercivity after annealing up to $300^{\circ} \mathrm{C}$ for all the samples is caused by the structural relaxation processes which leads to elimination of internal stresses induced in the films during their preparation. The minimal value of $H_{\mathrm{c}}$ was observed after annealing at $350^{\circ} \mathrm{C}$ due to crystallization of FeSi phase, however, low volume fraction of the phase was observed. Slight grain coarsening observed at $400^{\circ} \mathrm{C}$ caused smooth increase in $H_{c}$. Further grain coarsening at $450^{\circ} \mathrm{C}$ caused steep increase in $H_{\mathrm{c}}$. It can be explained by the fact that the grains are coupled only in two dimensions because thin thickness and grain size are of the same order of magnitude. This leads to an increase in the magnetocrystalline energy and therefore to higher values of $H_{\mathrm{c}}$. This process can be seen more clearly in the samples annealed at $500^{\circ} \mathrm{C}$ with higher grain size [3]. 


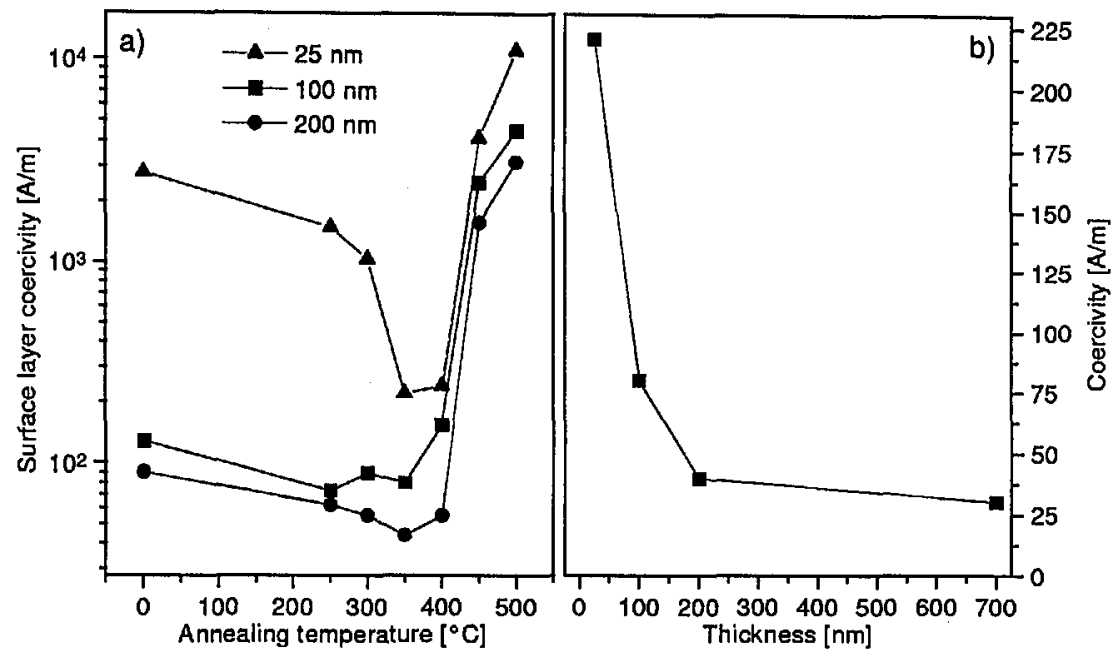

Fig. 2. (a) The dependence of surface layer coercivity on annealing temperature. (b) Thickness dependence of coercivity of the samples annealed at $350^{\circ} \mathrm{C}$.
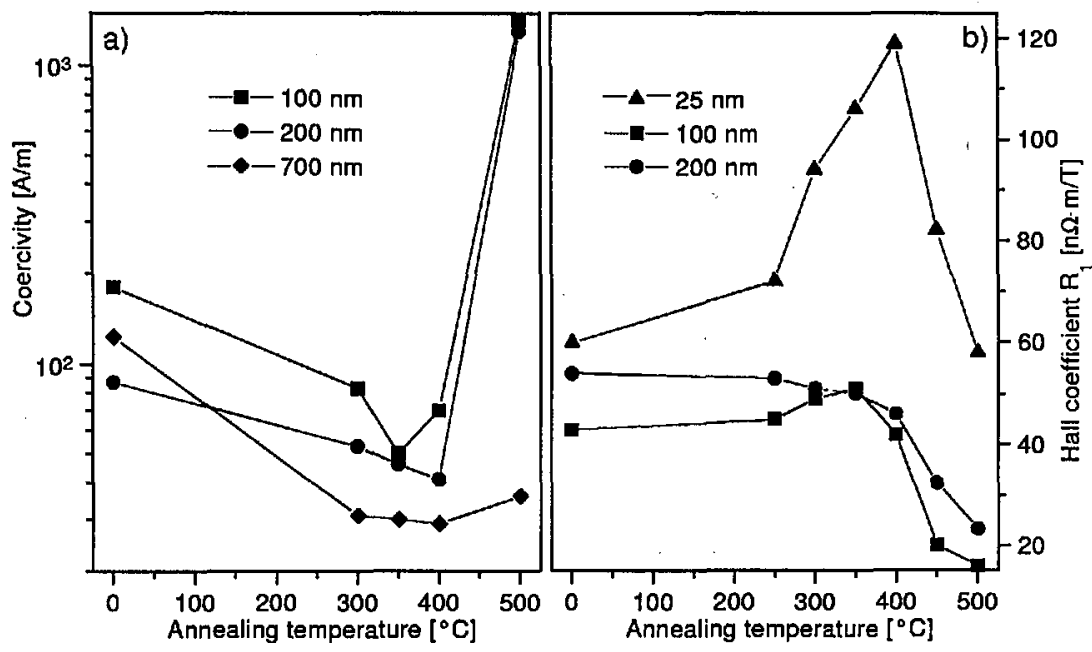

Fig. 3. (a) The dependence of bulk coercivity on annealing temperature. (b) The dependence of the Hall coefficient $R_{1}$ on annealing temperature.

Figure 2b illustrates thickness dependence of $H_{\mathrm{c}}$ after annealing at $350^{\circ} \mathrm{C}$.

Figure 3a shows the temperature dependence of bulk coercivity on film thickness. It can be seen that surface layer $H_{\mathrm{c}}$ and bulk $H_{\mathrm{c}}$ are almost of the same magnitude for samples up to $100 \mathrm{~nm}$ thick. On the other hand, the bulk value of $H_{\mathrm{c}}$ decreases with increasing film thickness and above $200 \mathrm{~nm}$ is lower than for surface one. It can be explained by the fact that the Kerr magnetooptical hysteresisgraph gives information from about $50 \mathrm{~nm}$ thick surface layer of the sample. Moreover, the values of $H_{\mathrm{c}}$ are significantly influenced by the surface roughness. There is also an interesting fact that value of $H_{\mathrm{c}}$ for $700 \mathrm{~nm}$ thick sample does not increase up 
to $500^{\circ} \mathrm{C}$. It can be attributed to significantly lower value of magnetocrystalline energy because of convenient ratio between thickness and grain size of crystals.

Figure 3b presents the temperature dependence of extraordinary Hall coefficient $R_{1}$ for all samples. Initial increase in $R_{1}$ could be connected with generation of clusters of crystalline phase [4]. The lower thickness, the more significant increase in $R_{1}$. It can be seen that dependence of $R_{1}$ for $200 \mathrm{~nm}$ sample is already typical as for amorphous ribbons [5].

\section{Conclusion}

1. No influence of film thickness on crystallization process in the range 25-700 nm after annealing was observed. Crystallization process starts at lower temperature as for finemet ribbon $\left(350^{\circ} \mathrm{C}\right)$ and typical nanocrystalline structure was observed at the temperature range $350-500^{\circ} \mathrm{C}$ but with higher grain size $(10-50 \mathrm{~nm})$ as for finemet-type ribbons.

2. It has been proved that grain size and thickness of the films influences the value of magnetocrystalline energy (due to two-dimensional coupling in the case that thickness of the film corresponds with grain size of crystals). The higher thickness, the lower magnetocrystalline energy and value of coercivity, respectively.

3. Hall effect measurements confirmed higher sensitivity for indication of generation of crystallization nuclei (clusters) for very thin films (of about $25 \mathrm{~nm}$ ).

\section{References}

[1] G. Suran, H. Ouahmane, J. Sztern, J. Magn. Magn. Mater. 140-144, 691 (1995).

[2] N. Kataoka, M. Hosokawa, A. Inoue, T. Masumoto, Jpn. J. Appl. Phys. 28, L462 (1989).

[3] A. Neuweiler, H. Kronmüller, J. Magn. Magn. Mater. 177-181, 1269 (1998).

[4] P. Kollár, J. Füzer, P. Matta, T. Śvec, M. Konč, J. Magn. Magn. Mater. 157/158, 213 (1996).

[5] J. Füzer, P. Matta, P. Kollár, P. Sovák, M. Konč, J. Magn. Magn. Mater. 157/158, 205 (1996). 